\title{
IMPLEMENTASI CLOUD COMPUTING SEBAGAI INFRASTRUKTUR LAYANAN MAIL SERVER PADA UNIVERSITAS KHAIRUN
}

\author{
Muhammad Aziz ${ }^{1}$, Achmad Fuad $^{2}$, Mohamad Jamil $^{3}$ \\ Program Studi Teknik Informatika, Fakultas Teknik, Universitas Khairun \\ Jl.Jati Metro, Kota Ternate Selatan \\ E-mail : Muhammadazis011@gmail.com¹,ad_4ss@yahoo.com², jamilkhairun@gmail.com³
}

\begin{abstract}
Cloud computing is one of the most frequently discussed topics, as many are interested in using it and the services they offer are also more diverse. With cloud computing provides convenience starting from the user, both small and large companies and developers engaged in IT. One of the cloud computing services such as infrastructure as a service in which there is service provision hardware infrastructure such as virtual CPU containing RAM or memory, processor, and disk storage, and virtual switches. With this infrastructure services can be developed into a cloud computing system for the provision of mail server because it can generate multiple virtual machine machine in accordance with the needs and save the cost of providing the device.
\end{abstract}

Keywords: Cloud Computing, Mail Server, Infrastructure as a service (IaaS)

Abstrak -- Cloud computing menjadi salah satu topik yang sering dibicarakan karena banyak yang mulai tertarik untuk menggunakannya serta layanan yang ditawarkan juga semakin beragam. Dengan cloud computing memberikan kemudahan mulai dari user, perusahaan baik kecil maupun besar serta developer yang bergerak dibidang IT. Salah satu layanan cloud computing seperti infrastructure as a service yang didalamnya terdapat layanan penyediaan infrasturkutur hardware seperti $C P U$ virtual yang berisi $R A M$ atau memory, processor, dan disk storage, serta switch virtual. Dengan layanan infrasturktur tersebut maka dapat dikembangkan menjadi sebuah sistem cloud computing untuk penyediaan mail server karena dapat menghasilkan beberapa mesin server virtual sesuai dengan kebutuhan serta menghemat biaya penyediaan device.

Kata Kunci: Cloud Computing, Server Email, Infrastruktur sebagai layanan (IaaS)

\section{PENDAHULUAN}

Cloud computing menjadi salah satu topik yang sering dibicarakan karena banyak yang mulai tertarik untuk menggunakannya serta layanan yang ditawarkan juga semakin beragam. Dengan cloud computing memberikan kemudahan mulai dari user, perusahaan baik kecil maupun besar serta developer yang bergerak dibidang IT. Kemudahan yang diberikan Cloud Computing antara lain adalah mudahnya menggunakan layanan yang disediakan, proses update untuk software yang digunakan juga mudah karena langsung update secara otomatis tanpa mesti satu persatu komputer harus di update [1].

Salah satu layanan cloud computing seperti infrastructure as a service yang didalamnya terdapat layanan penyediaan infrasturkutur hardware seperti CPU virtual yang berisi $R A M$ atau memory, processor, dan disk storage, serta switch virtual. Dengan layanan infrasturktur tersebut maka dapat dikembangkan menjadi sebuah sistem cloud computing untuk penyediaan mail server karena dapat menghasilkan beberapa mesin server virtual sesuai dengan kebutuhan serta menghemat biaya penyediaan device.
Sebagai penunjang untuk melakukan komunikasi melalui email dibutuhkan sebuah server yang khusus untuk melayani proses pengiriman surat elektronik yang disebut dengan mail server. Mail server merupakan salah satu fungsi server yang paling banyak digunakan di perusahaan. Hal ini mengingat fungsi email sendiri yang bisa mengurangi biaya surat menyurat, lebih efisien dibandingkan komunikasi dengan menggunakan handphone dan dapat menyertakan attachment yang berguna sebagai pelengkap dan dokumen tambahan terkait dengan isi email [2].

Berdasarkan latar belakang di atas penulis akan mencoba merancang dan mengimplementasikan teknologi cloud computing untuk penyediaan mail server pada Universitas Khairun guna membantu dalam meringankan beban kerja pada master server dan juga dalam biaya penyediaan sumber daya dan juga biaya operasional. Parameter yang digunakan untuk menganalisa performansi mail server adalah nilai transfer rate dan besar data yang bisa dikirimkan melalui server tersebut. 


\section{KAJIAN PUSTAKA}

\subsection{Cloud Computing}

Cloud computing merupakan evolusi yang mengadopsi virtualization, service-oriented architecture and utility computing. Cloud computing memungkinkan konsumen teknologi untuk memikirkan komputasi secara efektif dengan biaya minimal dan dapat diandalkan. Hal lain yang juga tidak perlu lagi dikhawatirkan oleh pengguna adalah tentang bagaimana membangunnya, cara kerjanya, siapa yang mengoperasikan atau dimana harus meletakannya [3].

\subsection{Jaringan Komputer}

Berdasarkan penjelasan dari ilmuwan bernama Forouzan di dalam bukunya yang berjudul Computer Network A Top Down Approach, dapat diperoleh defenisi mengenai jaringan komputer. Didefenisikan bahwa jaringan komputer merupakan hasil dari koneksi (hubungan) dari sejumlah perangkat atau komputer yang dapat saling berkomunikasi satu sama lain. Perangkat yang dimaksud dalam defenisi ini mencakup semua jenis perangkat komputer (komputer desktop, komputer jinjing, smartphone, $\mathrm{PC}$ tablet) dan perangkat penghubung [1].

\subsection{Virtualisasi}

Virtualisasi bisa diartikan sebagai pembuatan suatu bentuk simulasi dari sesuatu yang asalnya bersifat fisik, misalnya sistem operasi, perangkat penyimpanan data atau sumber daya jaringan. Sedangkan Virtualisasi server adalah penggunaan perangkat lunak yang memungkinkan satu perangkat keras untuk menjalankan beberapa sistem operasi dan services pada saat yang sama [4].

\subsection{VMware}

Suatu perangkat lunak atau software virtual machine yang biasanya untuk menciptakan dan mensimulasikan pc secara virtual dengan cara mengkloning nya.Fungsi dan kegunaan vmware virtual machine biasanya untuk mencoba aplikasi, develop, melakukan percobaan lainnya yang biasanya jika kita lakukan di guest $O S$ yang artinya OS didalam OS dengan menggunakan vmware. Di VMware kita bisa melakukan percobaan dengan menggunakan sistem OS apapun mulai dari windows, mac, linux, install mikrotik di vmware dan lain sebagainya. Kita bisa bereksperimen tanpa harus kehilangan atau kerusakan pada OS utama. Intinya fungsi VMware dapat menjalankan banyak sistem operasi atau OS dalam satu PC atau laptop [5].

\section{5. vSphare Client}

vSphere Client adalah software aplikasi desktop windows OS yang berfungsi sebagai tool untuk melakukan pengaturan dan pengelolaan satu ESXi host dari secara remote komputer lain dengan tampilan GUI (Graphical User Interface), diantaranya untuk membuat virtual machine, deployment virtual appliance, setting konfigurasi virtual switch untuk network bagi virtual machine, datastore sebagai shared storage bagi virtual machine, dan fungsi lainnya. vSphere Client hanya ada dalam versi windows-based, yaitu hanya bisa di install di sistem operasi windows [3].

\subsection{Email}

Electronic mail atau email adalah metode pengiriman surat melalui jaringan internet. Sistematika penggunaan email tidak jauh berbeda dengan surat konvesional. Surat terdiri dari nama pengeirim, alamat yang dituju dan isi surat. Perbedaan menggunakan email terletak pada media pengirim yang digunakan yakni menggunakan jaringan internet. Sebelum pengguna dapat memanfaatkan email, terlebih dahulu seorang pengguna harus mendaftarkan dirinya pada sebuah server atau administrator. Setelah mendaftarkan dirinya pengguna akan mendapatkan account yang digunakan masuk pada sebuah layanan email dimana pengguna dapat menulis, menerima, dan mengirim email. Kelebihan yang dimiliki oleh email adalah menghemat biaya karena email tidak perlu menggunakan kertas sebagai media penulisannya. Email hanya memerlukan sebuah komputer yang tersambung dalam jaringan internet [6].

\subsection{Mail Server}

Sebuah mail server terdiri dari beberapa komponen yakni MTA (Mail Transfer Agent), MDA (Mail Delivery Agent), dan MRA (Message Retrieval Agent). MTA bertindak sebagai pengirim dan penerima pesan yang melalui mail server melalui SMTP. Email yang diterima oleh MTA akan disimpan dalam sebuah antrian kemudian $M D A$ dipanggil untuk mengirimkan dan menyimpan email sesuai alamat penerima yang dituju. Ketika pengguna ingin menbaca email dia dapat masuk atau log in menggunakan akun yang sudah terdaftar.

MRA dirancang sebagai MUA (Message User Agent) dimana pengguna dapat mengakses akunnya dari jarak jauh melalui internet. Sementara IMAP membuat akses yang mungkin sehingga pengguna dapat mengakses email yang disimpan dalam sebuah server [6].

\subsection{MD5}

MD5 di desain oleh Ronald Rivest pada tahun 1991 untuk menggantikan hash function sebelumnya MD4. Pada tahun 1996 sebuah kecacatan ditemukan dalam desainnya, walau bukan kelemahan fatal pengguna kriptografi mulai menganjurkanmenggunakan algoritma lain. Seperti 
SHA-1 pada tahun 2004, kecacatan - kecacatan yang lebih serius ditemukan [7].

Setelah pembuatan sistem pendataan koperasi berbasis web, terdapat beberapa saran yang bisa diberikan, yaitu:

1. Dapat menambahkan data tentang kegiatan koperasi per bulan seperti data pendapatan per bulan, untuk dapat melihat keatifan setiap bulan.

2. Data anggota juga sebaiknya dapat diinput ke dalam sistem.

3. Agar point 1 dan 2 di atas maka sebaiknya diberikan hak akses untuk koperasi yang ada terhadap sisstem pendataan koperasi ini.

\subsection{Fungsi Hash}

Fungsi hash merupakan fungsi yang menerima masukan bermacam - macam dan menghasilkan string keluaran yang panjangnya tetap. Panjang string keluaran biasanya berukuran jauh lebih kecil dari pada ukuran masukan.

Fungsi hash satu arah merupakan fungsi hash yang bekerja satu arah, sekali pesan diubah menjadi message digest makan tidak dapat lagi dikembalikan menjadi pesan semula atau irreversible.

Fungsi hash satu arah harus memnuhi sejumlah kriteria berikut :

1. Preimage resistant, yaitu tidak mungkin menemukan pesan masukan berdasarkan sebuah message digest.

2. Second preimage resistant, yaitu tidak mungkin menemukan dua masukan berbeda yang dapat menghasilkan message digest yang sama.

3. Collison resitant, yaitu tidak tidak mungkin menemukan dua pesan masukan dengan nilai hash yang sama.

4. Fungsi hash mudah dihitung.

5. Panjang message digest tetap.

6. Fungsi hash dapat diterapkan pada pesan masukan dengan panjang sebarang [7].

\subsection{Rata-Rata Hitung ( Mean )}

Rata-rata hitung adalah nilai rata-rata dari data-data yang ada. Rata-rata hitung dari populasi diberi simbol $\mu$ (miu). Rata-rata hitung dari sampel diberi simbol $\bar{X}$ (eks bar). (Rahmat, 2012).

Untuk mencari nilai rata-rata dari transfer rate, dan waktu pengiriman bisa menggunakan rumus dibawah ini : :

$$
\bar{X}=\frac{X_{1}+X_{2}+X_{3}+\cdots+X n}{N}
$$

Keterangan : $\bar{X}=$ rata - rata

$$
\mathrm{Xn} \text { = banyak data (data } \mathrm{k}-1 \text { sampai }
$$

$\mathrm{k}-\mathrm{n})$

$$
\mathrm{N}=\text { jumlah data }
$$

Untuk menghitung presentase nilai integritas data yang dikirim ke user digunakan rumus berikut :

$\mathrm{I}$

$$
=\frac{x}{y} \times 100 \%
$$

$$
\begin{aligned}
\text { Keterangan : } \mathrm{I} & =\text { integritas data } \\
\mathrm{x} & =\text { besar file yang diterima } \\
\mathrm{y} & =\text { besar file yang dikirim }
\end{aligned}
$$

\section{METODE PENELITIAN}

\subsection{Studi Literatur}

Pada tahap ini dilakukan studi literatur dengan mengumpulkan informasi yang telah ada tentang penelitian-penelitian yang memiliki keterkaitan dengan masalah yang akan diteliti. Referensi informasi yang digunakan berupa tugas akhir, jurnal, artikel, dan tulisan-tulisan lainnya yang membahas tentang sistem cloud computing serta aplikasi yang dapat digunakan dalam sistem tersebut.

\subsection{Metode Pengumpulan Data}

Adapun metode pengumpulan data yang penulis gunakan dalam penulisan laporan skripsi adalah sebagai berikut:

1. Observasi

Dimana penulis mengadakan penelitian dengan cara mengadakan pengamatan langsung aktifitas sehari-hari pada objek dan melakukan pencatatan atas fakta- fakta yang ada, baik secara langsung maupun tidak langsung dengan tujuan agar dapat mengetahui apa saja yang dianggap penting untuk dijadikan bahan masukan.

2. Wawancara

Dimana penulis mengadakan tanya jawab secara langsung dengan pegawai untuk mengetahui sistem yang ada saat ini dan kesulitan apa yang dihadapi.

3. Studi Kepustakaan

Mengacu pada studi literatur diatas, maka studi kepustakaan ini dilakukan penulis untuk mencari data-data yang berkaitan dengan judul skripsi yang nanti penulisan buat,untuk menunjang terselesaikannya skripsi ini.

\subsection{Desain Sistem}

Rancangan sistem menggunakan metode PPDIOO yang dikembangkan oleh CISCO untuk desain sistem jaringan. Selanjutnya implementasi server cloud dengan menggunakan VMWare. 


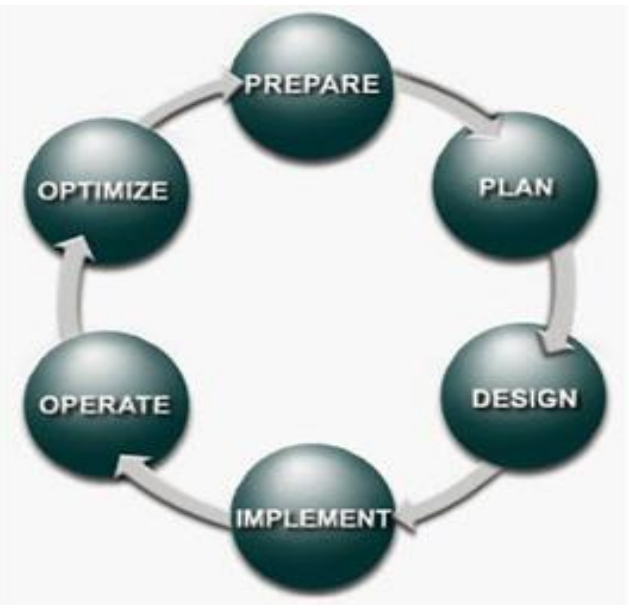

Gambar 3.1 Skema Metodologi PPDIOO [8].

\section{Prepare}

Fase ini meliputi data-data apa saja yang akan menjadi penentuan dalam syarat jaringan, merumuskan strategi jaringan dan menyarankan konseptual arsitektur jaringan. Seperti tanya jawab dan observasi.

2. Plan

Fase ini dilakukan analisis kebutuhan perangkat pendukung sebelum merancang sebuah sistem jaringan mail server dengan menggunakan teknologi cloud computing. Maka ditambahkan aplikasi-aplikasi pendukung mail server seperti VMWare, vSphere Client, centOS, dan IredMail.

3. Design

Fase ini adalah tahap dimana terdapat penggambaran design topologi yang diimplementasikan pada cloud jenis private dengan layanan IaaS untuk membangun sebuah sistem mail server.

4. Implement

Implement merupakan fase dimana ini akan diterapkan semua yang telah direncanakan dan di design sesuai dengan hasil analisa. Fase implement merupakan tahapan yang menentukan berhasil atau gagalnya sistem yang akan dibangun.

5. Operate

Operate merupakan fase dilakukannya uji coba sistem yang dijalankan secara realtime serta dilakukan dengan melakukan uji coba penggunaan server cloud untuk penyedia mail server. Pada fase ini juga dapat memecahkan masalah yang timbul selama proses berlangsung, juga dilakukan monitoring pada kinerja sistem agar dapat mengetahui kekurangan.

6. Optimaze

Optimaze adalah tahap terakhir dimana setelah melakukan analisis maka akan diperbarui sistem yang telah dibangun, hal ini bertujuan untuk mencapai peningkatan kinerja sistem yang optimal dan dapat menyelesaikan masalah.

Tabel 3.1.Spesifikasi Hardware

\begin{tabular}{|c|c|c|c|}
\hline No & $\begin{array}{c}\text { Perangkat } \\
\text { Keras }\end{array}$ & Spesifikasi & Keterangan \\
\hline 1. & Server 1 & $\begin{array}{l}\text { Dell Inc. Model } \\
\text { Power Edge } \\
\text { R230 4 CPUs X } \\
3 \mathrm{GHz} \text { Intel (R) } \\
\text { Xeon(R) CPU } \\
\text { E3-1220 v5 @ } \\
3.00 \mathrm{GHz}\end{array}$ & Server Fisik \\
\hline 2. & Server 2 & $\begin{array}{l}\text { Intel }{ }^{\circledR} \text { Core }{ }^{\text {TM }} \\
\text { i3-2330M CPU } \\
\text { @ } 2.20 \mathrm{GHz} \text {, } \\
\text { 2.00 GB RAM }\end{array}$ & $\begin{array}{l}\text { Server } \\
\text { Virtual }\end{array}$ \\
\hline
\end{tabular}

Tabel 3.2.Spesifikasi Software

\begin{tabular}{|l|l|l|}
\hline \multicolumn{1}{|c|}{ Jenis } & \multicolumn{1}{c|}{ Nama } & \multicolumn{1}{c|}{ Keterangan } \\
\hline OS & $\begin{array}{l}\text { Centos 6.5 } \\
\text { Minimal } \\
\text { install }\end{array}$ & Sistem operasi \\
\hline $\begin{array}{l}\text { Software } \\
\text { cloud, } \\
\text { Virtualisasi }\end{array}$ & $\begin{array}{l}\text { VMware Exsi } \\
\text { 6.0, Vsphare } \\
\text { Client }\end{array}$ & $\begin{array}{l}\text { Perangkat lunak } \\
\text { virtual } \\
\text { management }\end{array}$ \\
\hline $\begin{array}{l}\text { Software } \\
\text { Mail }\end{array}$ & IredMail & $\begin{array}{l}\text { Perangkat Lunak } \\
\text { Aplikasi Mail }\end{array}$ \\
\hline
\end{tabular}

\subsection{Topologi Perancangan}

Pembuatan sistem cloud computing untuk penyediaan mail server ini menggunakan Centos 6.5 sebagai OS pendukung, VMware Exsi 6.0 
sebagai perangkat lunak virtual management dan

IredMail sebagai perangkat lunak aplikasi email.

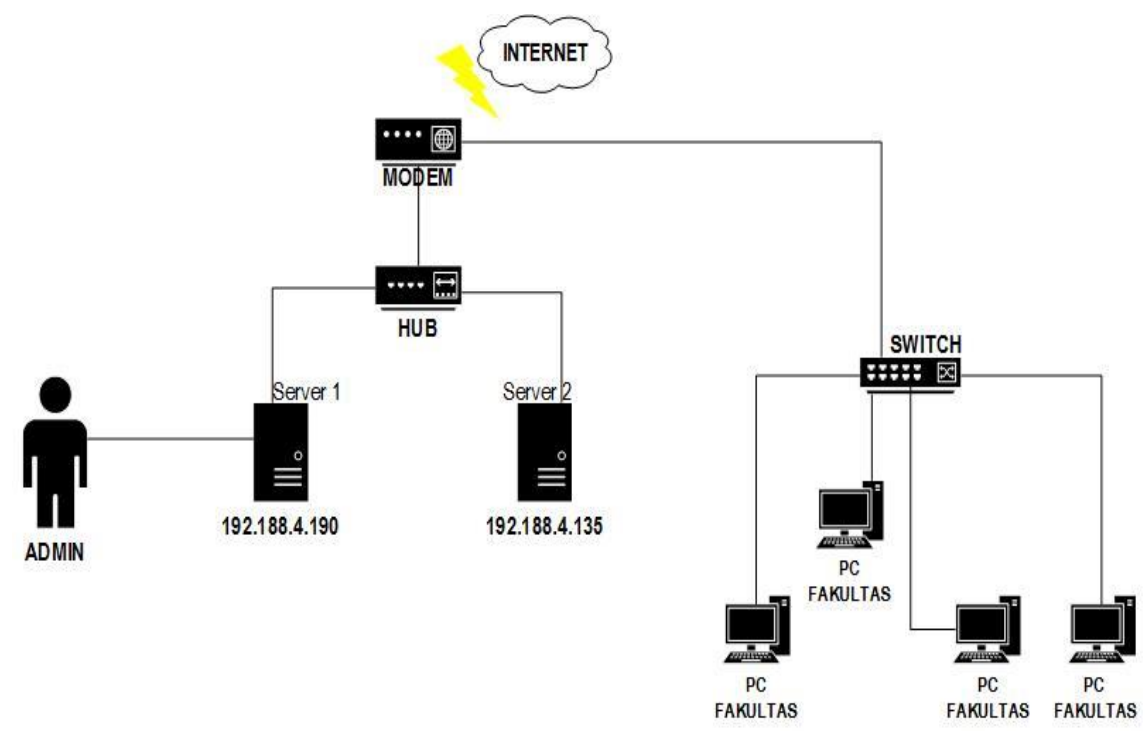

Modem disini berfungsi sebagai penghubung jaringan internet yang kemudian dihubungkan ke satu buah hub untuk di hubungkan lagi ke server, dan ada juga dari modem ke satu buah switch sebagai pembagi sinyal menggunakan kabel UTP ke masing-masing fakultas.

Admin disini berfungsi sebagai orang yang akan mengakses server fisik untuk bisa mengaktifkan server virtual (mail server), admin juga yang nantinya mengelola secara penuh server virtual (mail server) seperti pembagian bandwith, add user, dan add admin. Server fisik akan kita instal VMWare esxi kemudian ada beberapa setup seperti mengisi alamat IPv4, subnet mask, default gateway, primary DNS server, alternate DNS server dan memasukan user name dan password.Server virtual (mail server) akan dinstal centOS kemudian ada juga beberapa setup yang hampir sama pada server fisik, akan tetapi pada server virtual (mail server) ini akan kita berikan IP yang berbeda dari IP server fisik, dimana IP ini yang nantinya dipakai oleh user untuk bisa mengakses mail server yang akan dibuat. Fakultas nantinya bisa mengakses sistem mail server dengan IP yang sudah di setup pada server virtual menggunakan mozilla firefox dengan alamat https//:192.188.4.134/mail.

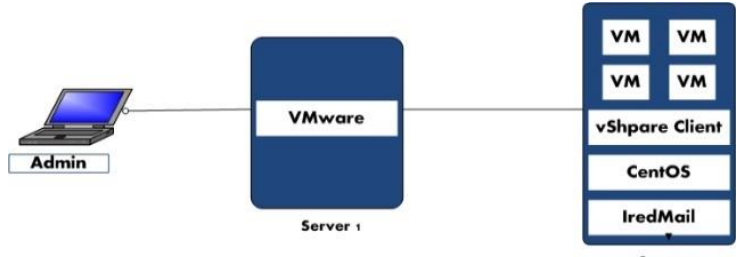

Gambar 3.3 Desain Logical Cloud
Server 2
Pada desain logical cloud terdapat tiga bagian yaitu admin, server 1, dan server 2. Admin berfungsi sebagai orang yang nantinya mengelola server fisik dan server virtual pada sistem ini. Server satu terdapat VMware sebagai aplikasi pendukung untuk pembuatan server virtual. Server dua di dalamnya terdapat vShpare Client sebagai aplikasi untuk mengakses server virtual, CentOS sebagai sistem operasi pendukung untuk menjalankan perintah-perintah, dan IredMail sebagai layanan penyediaan mail server.

\section{HASIL PEMBAHASAN}

\subsection{Implementasi}

Pada tahap ini akan dilakukan penginstalan dan setup software-software pendukung dalam pembuatan sistem mail server berbasis cloud computing, seperti VMWare, vShpere client, centOS, dan Iredmail.

\subsection{Pengujian dan Analisa}

Tahap pengujian mail server ini melalui dua skenario pengujian. Skenario pengujian dibedakan berdasarkan parameter yang digunakan. Pada skenario pertama menggunakan beberapa parameter yakni besar data, transfer rate, jumlah pengguna dan waktu pengiriman. Sedangkan pada skenario kedua menggunakan integritas data dan transfer rate yang dikirimkan sebagai parameternya.

\section{Skenario Pengujian Dengan 25 User}

Pada pengujian dengan menggunakan 25 user ini sama saja dengan pengujian pertama dengan 2 user, dimana besar data dan banyaknya pengujian 
tetap sama yang membedakan hanya jumlah user yang menjadi tujuan pengiriman.

a. Pengujian Dengan Besar Data 5 MB Untuk 25 User

Tabel 4. 1 Pengujian Data $5 \mathrm{MB}$

\begin{tabular}{|l|l|l|l|l|}
\hline No & Jam & $\begin{array}{l}\text { Besar } \\
\text { Data }\end{array}$ & $\begin{array}{l}\text { Transfer } \\
\text { rate }\end{array}$ & $\begin{array}{l}\text { Waktu } \\
\text { Pengiriman }\end{array}$ \\
\hline 1 & 11.02 & $5 \mathrm{MB}$ & 91,01 & 36,04 \\
\hline 2 & 14.12 & $5 \mathrm{MB}$ & 91,13 & 36,26 \\
\hline 3 & 13.24 & $5 \mathrm{MB}$ & 90,46 & 37,51 \\
\hline 4 & 09.45 & $5 \mathrm{MB}$ & 90,47 & 37,51 \\
\hline 5 & 12.37 & $5 \mathrm{MB}$ & 91,05 & 36,01 \\
\hline
\end{tabular}

b. Pengujian Dengan Besar Data 10 MB Untuk 25 User.

Tabel 4.2 Pengujian Data 10 MB

\begin{tabular}{|l|l|l|l|l|}
\hline No & Jam & $\begin{array}{l}\text { Besar } \\
\text { Data }\end{array}$ & $\begin{array}{l}\text { Transfer } \\
\text { rate }\end{array}$ & $\begin{array}{l}\text { Waktu } \\
\text { Pengiriman }\end{array}$ \\
\hline 1 & 13.00 & $10 \mathrm{MB}$ & 82,96 & 45,03 \\
\hline 2 & 12.30 & $10 \mathrm{MB}$ & 82,32 & 45,28 \\
\hline 3 & 10.07 & $10 \mathrm{MB}$ & 81,98 & 46,15 \\
\hline 4 & 12.00 & $10 \mathrm{MB}$ & 82,21 & 45,35 \\
\hline 5 & 15.54 & $10 \mathrm{MB}$ & 82,65 & 45,12 \\
\hline
\end{tabular}

c. Pengujian Dengan Besar Data 15 MB Untuk 25 User.

Tabel 4.3 Pengujian Data 15 MB

\begin{tabular}{|l|l|l|l|l|}
\hline No & Jam & $\begin{array}{l}\text { Besar } \\
\text { Data }\end{array}$ & $\begin{array}{l}\text { Transfer } \\
\text { rate }\end{array}$ & $\begin{array}{l}\text { Waktu } \\
\text { Pengiriman }\end{array}$ \\
\hline 1 & 11.00 & $15 \mathrm{MB}$ & 74,87 & 52,32 \\
\hline 2 & 15.47 & $15 \mathrm{MB}$ & 74,46 & 52,78 \\
\hline 3 & 09.45 & $15 \mathrm{MB}$ & 74,98 & 52,17 \\
\hline 4 & 12.30 & $15 \mathrm{MB}$ & 75,15 & 53,06 \\
\hline 5 & 11.34 & $15 \mathrm{MB}$ & 75,25 & 53,21 \\
\hline
\end{tabular}

d. Pengujian Dengan Besar Data 20 MB Untuk 25 User.

Tabel 4.4 Pengujian Data 20 MB

\begin{tabular}{|l|l|l|l|l|}
\hline No & Jam & $\begin{array}{l}\text { Besar } \\
\text { Data }\end{array}$ & $\begin{array}{l}\text { Transfer } \\
\text { rate }\end{array}$ & $\begin{array}{l}\text { Waktu } \\
\text { Pengiriman }\end{array}$ \\
\hline 1 & 15.28 & $20 \mathrm{MB}$ & 66,43 & 59,18 \\
\hline 2 & 11.17 & $20 \mathrm{MB}$ & 66,68 & 59,04 \\
\hline 3 & 10.35 & $20 \mathrm{MB}$ & 67,04 & 59,58 \\
\hline 4 & 12.40 & $20 \mathrm{MB}$ & 66,25 & 59,21 \\
\hline 5 & 16.14 & $20 \mathrm{MB}$ & 67,85 & 59,34 \\
\hline
\end{tabular}

e. Pengujian Dengan Besar Data 25 MB Untuk 25 User.

Tabel 4.5 Pengujian Data 25 MB

\begin{tabular}{|l|l|l|l|l|}
\hline No & Jam & $\begin{array}{l}\text { Besar } \\
\text { Data }\end{array}$ & $\begin{array}{l}\text { Transfer } \\
\text { rate }\end{array}$ & $\begin{array}{l}\text { Waktu } \\
\text { Pengiriman }\end{array}$ \\
\hline 1 & 10.42 & $25 \mathrm{MB}$ & 54,32 & 63,08 \\
\hline 2 & 11.57 & $25 \mathrm{MB}$ & 54,48 & 63,01 \\
\hline 3 & 14.05 & $25 \mathrm{MB}$ & 54,34 & 63,08 \\
\hline 4 & 11.36 & $25 \mathrm{MB}$ & 54,65 & 62,87 \\
\hline 5 & 12.44 & $25 \mathrm{MB}$ & 54,45 & 62,91 \\
\hline
\end{tabular}

f. Pengujian Dengan Besar Data 30 MB Untuk 25 User.
Tabel 4.6 Pengujian Data 30 MB

\begin{tabular}{|l|l|l|l|l|}
\hline No & Jam & $\begin{array}{l}\text { Besar } \\
\text { Data }\end{array}$ & $\begin{array}{l}\text { Transfer } \\
\text { rate }\end{array}$ & $\begin{array}{l}\text { Waktu } \\
\text { Pengiriman }\end{array}$ \\
\hline 1 & 12.12 & $30 \mathrm{MB}$ & 47,26 & 69,82 \\
\hline 2 & 14.25 & $30 \mathrm{MB}$ & 47,10 & 69,86 \\
\hline 3 & 10.55 & $30 \mathrm{MB}$ & 47,64 & 69,40 \\
\hline 4 & 16.13 & $30 \mathrm{MB}$ & 47,67 & 69,38 \\
\hline 5 & 13.14 & $30 \mathrm{MB}$ & 47,34 & 70,03 \\
\hline
\end{tabular}

Tabel diatas adalah hasil dari pengujian pada skenario pertama dengan menggunakan 25 user, dimana pada pengujian ini besar data yang diuji adalah $5 \mathrm{MB}, 10 \mathrm{MB}, 15 \mathrm{MB}, 20 \mathrm{MB}, 25 \mathrm{MB}$, $30 \mathrm{MB}$, dengan waktu pengujian yang berbedabeda dikarenakan aplikasi yang digunakan sering terjadi error pada saat pengujian. Selanjutnya akan dihitung rata-rata waktu pengiriman dan rata-rata transfer rate dari data yang sudah ada diatas. Berikut adalah hitungan rata-rata dari transfer rate dan waktu pengiriman untuk besar data $5 \mathrm{MB}$.

Rata - rata hitung transfer rate $\bar{X}$

$=\frac{91,01+91,13+90,46+90,47+91,05}{5}$

$=90,824 \mathrm{KBps}$

Rata - rata hitung waktu pengiriman $\bar{X}$

$=\frac{36,04+36,20+37,51+37,51+36,01}{5}$

$=36,65 \mathrm{~s}$

Tabel 4.7 Hasil Rata-Rata 25 User

\begin{tabular}{|c|c|c|}
\hline Besar file & $\begin{array}{c}\text { Transfer rate } \\
\text { rata-rata (kbps) }\end{array}$ & $\begin{array}{c}\text { Waktu } \\
\text { pengiriman } \\
\text { rata-rata (s) }\end{array}$ \\
\hline 5 & 90,824 & 36,65 \\
\hline 10 & 82,424 & 45,38 \\
\hline 15 & 74,934 & 52,70 \\
\hline 20 & 66,85 & 59,27 \\
\hline 25 & 54,448 & 62,99 \\
\hline 30 & 47,402 & 69,69 \\
\hline
\end{tabular}

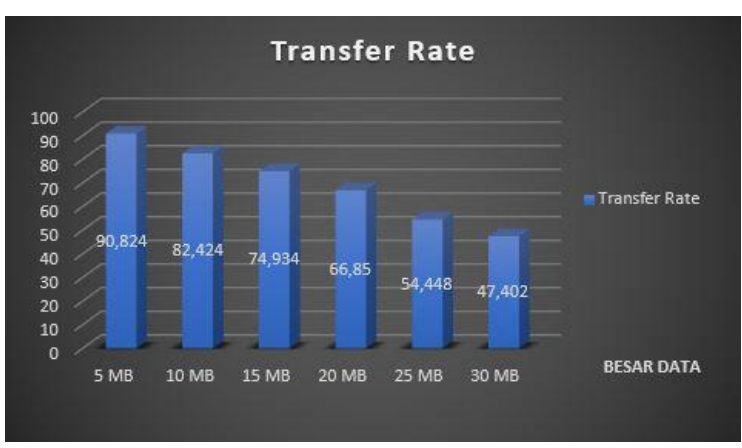

Gambar 4.1 Grafik Hasil Pengujian Transfer rate 25 User 


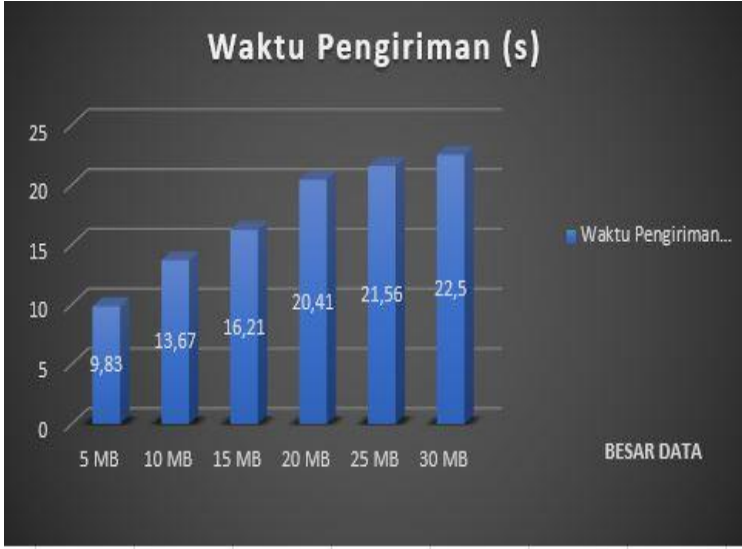

Gambar 4.2 Grafik Hasil Pengujian Waktu Pengiriman 25 User

Pada pengujian dengan menggunakan 25 user bahwa nilai transfer rate dan waktu pengiriman sedikit menurun dibandingkan dengan menggunakan 2 user, ini disebabkan banyaknya email tujuan pengiriman yang menyebabkan server menjadi sibuk.

\subsection{Analisa}

Tahap awal saat penginstalan dan setup VMWare tidak ada kendala yang terjadi, begitu juga dengan penginstalan centos dan juga iredmail. Hanya saja saat melakukan penginstalan iredmail harus sesuai dengan versi yang terbaru, jika versi lama yang di download maka saat melakukan penginstalan akan terjadi error.

Untuk cara penginstalan dan setup Vmware, centOS dan juga iredmail bisa dilihat pada bab 4 . Setelah semua perangkat lunak yang dibutuhkan sudah terinstal maka selanjutnya dilakukan pengujian dan analisa dimana ada dua tahapan pengujian. Adapun besaran data yang diujikan berbeda-beda hal ini untuk melihat kecepatan transfer dan waktu pengiriman dari mail server itu sendiri.

Analisa pada pengujian skenario pertama menggunakan aplikasi ServerTool dapat dilihat pada gambar 4.30 diatas. Pengujian diatas bertujuan untuk mengetahui transfer rate saat mail server mengirim data. Hasil pengujian pada skenario pertama dapat dilihat pada gambar grafik 4.31 diatas dimana nilai transfer rate mengalami penurunan atau sebanding dengan besar file yang dikirimkan.

Sedangkan pada pengujian dengan menggunakan 25 user ini terlihat bahwa nilai transfer rate dan waktu pengiriman sedikit menurun dibandingkan dengan menggunakan 2 user, ini disebabkan banyaknya email tujuan pengiriman yang menyebabkan server menjadi sibuk.

Analisis selanjutnya pada skenario pengujian kedua, dimana untuk pengujian kedua ini yang akan dilihat adalah nilai integritas data dan nilai transfer rate. Hasil pengujian pada skenario kedua ini dapat dilihat pada gambar grafik 4.36 dan 4.37 diatas, dimana nilai integritas data mencapai $100 \%$ atau besar data yang dikirimkan sesuai dengan besar data yang diterima oleh user, hal ini juga bisa dibuktikan dengan melihat angka-angka pada kolom perbandingan aplikasi MD5 checksums.

\section{KESIMPULAN DAN SARAN}

\subsection{Kesimpulan}

Kesimpulan yang didapat pada penelitian implementasi cloud computing sebagai infrastruktur layanan mail server pada universitas khairun adalah :

1. Penulis berhasil membuat dan mengimplementasikan mail server berbasis cloud dengan layanan infrastructure as a service (IAAS).

2. Untuk mengetahui nilai transfer rate, waktu pengiriman, dan integritas data dilakukan 2 tahapan pengujian dimana dalam tiap pengujian diberikan besar data yang berbeda, hasilnya nilai transfer rate dan waktu pengiriman selalu meningkat atau sesuai degan besar data yang dikirimkan. Untuk integritas data hasil yang didapatkan mencapai $100 \%$, dimana besaran data yang dikirimkan sesuai dengan besaran data yang diterima.

3. Pada pengujian pertama untuk mengetahui nilai transfer rate dan waktu pengiriman besar data yang diujikan berbeda-beda, untuk tiap data dilakukan 5 kali pengujian kemudian akan dihitung nilai rata-rata transfer rate dan waktu pengiriman untuk masing-masing besar data yang diujikan. Hasil yang didapatkan nilai transfer rate selalu meningkat sesuai dengan besar data yang dikirimkan.

4. Untuk pengujian kedua yang akan dilihat adalah nilai integritas data yang dicapai, dimana besar data yang sudah ditentukan akan dikirim ke semua user secara bersamaan dan dilakukan pengecekan pada email masing-masing user. Setelah melakukan pengecekan nilai integritas untuk masing-masing besar data mencapai $100 \%$, dan dapat dibuktikan dengan aplikasi MD5 checksums.

\subsection{Saran}

Adapun saran-saran terhadap penelitian ini agar kedepannya bisa dikembangkan lebih baik lagi adalah :

1. Penggunaan sistem operasi untuk penyediaan mail server bisa ditambahkan lagi tidak hanya terbatas pada satu sistem operasi saja.

2. Untuk layanan infrastructure as a service (IAAS) bisa dikembangkan lagi untuk 
menyediakan layanan-layanan yang lainnya.

\section{DAFTAR PUSTAKA}

[1]. I Putu Agus Eka Pratama, S.T., M.T, 2014., Smart City Beserta Cloud Computing dan Teknologi-Teknologi Pendukung Lainnya.

[2]. Moh Halimi, Barlian Henryranu P, Gembong Edhi Setiawan, 2013., Rancang Bangun Mail Server Dalam Jaringan Lokal Menggunakan Embedded System.

[3]. Moh. Jamil, Rosihan, Ahmad Fuad, 2016., Cloud Computing Teori dan Aplikasi.

[4]. I Komang A. Mogi, Putu Gede Surya C. N, I Made Agus S, 2015.,Implementasi Private Cloud Computing Sebagai Layanan Infrastructure As a pService (IaaS) Menggunakan OpenStack.

[5]. Iwan Sofana, 2012., Cloud Computing Teori dan Praktik (OpenNebula, VMware, dan Amazon AWS).

[6]. Moh Halimi, Barlian Henryranu P, Gembong Edhi Setiawan, 2013., Rancang Bangun Mail Server Dalam Jaringan Lokal Menggunakan Embedded System.

[7]. Candara Alim Sutanto 2011, Alogoritma Fungsi Hash Baru dengan Menggabungkan MD5, SH-1 dan Pernyataan Pesan Asli.

[8]. Sulistyowati Luchi, Dkk, 2012., Implementasi Cloud Computing Sebagai Infrastructure As a Service Untuk Penyedia Web Server. 